\title{
SUSTAINABLE AGRICULTURE IN EASTERN ETHIOPIA
}

\author{
Hiwot Mekonnen MESFIN
}

\author{
Address: \\ School of Agricultural Economics and Agribusiness, Haramaya University, Ethiopia \\ E-mail: hiwot.jambo@gmail.com
}

\begin{abstract}
Agriculture is characterized by a growing use of chemicals, such as fertilizers, pesticides and herbicides that are negatively affecting human health and the environment. Despite that, the Ethiopian government promotes the use of those chemicals in an attempt to increase yield and improve farmer's livelihoods. On the other hand, environmental researchers argue that, equivalent yield can be obtained by using sustainable agricultural practices and produce safe food. Unfortunately, the "traditional" sustainable agricultural practices are being replaced by chemical intensive practices as the later is largely promoted. Therefore, it is important to trigger policy towards the promotion of "traditional" sustainable agricultural practices through research. This study, by using 299 randomly selected households from Eastern Ethiopia, unravels the factors that influence the use of crop rotation in Eastern Ethiopia. The results can serve policy makers by identifying the relevant variables and help them design successful intervention strategies. Based on the result, older age (older than 37 years), use of irrigation, distance to FTC, land size and farmers perception towards soil fertility are found to positively affect the decision to practice crop rotation. On the other hand, young age (younger than 37 years) and distance from market are found to hinder the decision of farmers to practice crop rotation. Sustainable agriculture can be brought back on track by creating a platform for older farmers to share their experiences with younger farmers and diverting some of the attention given to chemical fertilizers towards the "traditional" and sustainable practices.
\end{abstract}

Keywords: Crop Rotation, Sustainable Agriculture, Probit Model, Ethiopia

JEL: Q2, Q5

\section{INTRODUCTION}

Following the Growth and Transformation Plan (GTP), to increase productivity of farmers and insure food security, Ethiopia is planning to double its fertilizer consumption to 1.2 million metric tons (IFDC, 2012). Lengthy application of chemical fertilizers, such as urea, increases soil acidity by reducing the PH level. Acidic soil poses a serious problem for humanity as most crops and plants cannot grow in acidic soil. Soil acidity is becoming a big concern for developing countries that have chemical intensive large farms. For example, $50 \%$ of Australia's surface soil has a PH of 5.5, which is below desired. Amelioration of acidic soil is expensive and difficult which will negatively affect the sustainability of agriculture (NLWRA, 2001).

Agriculture in Eastern Ethiopia is dominated by cereals, mainly maize and sorghum. Groundnuts and Khat are also widely cultivated. The Ethiopian government gives due attention to the distribution and wide adoption of chemical fertilizers to increase the yield of smallholder farmers. Despite the widespread distribution, farmers are facing soil degradation and unsatisfactory yield. Farmers in the study area are found be sceptical of chemical fertilizer application arguing that it distorts the fertility of soil (Mekonnen et al., 2016). Therefore, focus towards sustainable agricultural practices, such as, crop rotation, application of manure, crop diversification, minimum tillage and etc. can serve as an alternative policy strategy. Studies have shown that by using crop rotation, farmers can obtain yield equivalent to that of obtained by chemical fertilizer application (Bullock, 1992).

Crop rotation is the cultivation of different crops in a specified order, over specified period of time, in order to enhance the productivity of soil. Crop rotation has been used by farmers in ancient China, Rome and Greece with long time spans in between the cultivation of different crops. In around 1950s farmers started replacing crop rotation by chemical fertilizers, high yielding seed varieties, and pesticides and herbicides to increase their harvest and control weeds and pests. Despite this fact, some farmers still use crop rotation in shorter time intervals. For example in the US, about $80 \%$ of farmers rotate maize (corn) with soybean in $2: 1$ rotation. The most recommended rotation by scientists is, to grow cereals and then follow that with pastures, cover crops and green manures. However, most farmers do not find that suggestion economical. Therefore, they adopt the two or three crops rotation instead (Baldwin, 2006).

Crop rotation is an effective practice that can replace the use of pesticides and herbicides. In addition, crop rotation plays an immense role in maintaining soil moisture content, reducing soil erosion and minimizing the amount of water required for irrigation. Those advantages make the practice attractive for farmers, and other stakeholders interested in promoting sustainable agriculture in developed countries (Cardina et al, 2002; Liu et al, 2010). However, sustainable agriculture is not getting enough attention by the Ethiopian government. 
Based on the existing literature, it is well established that farmers can enhance the quality of their soil and maintain their productivity, by using the legume-cereal rotation practice. Promoting sustainable yield enhancing technologies should be at the center of any development agenda for countries like Ethiopia, where they are still struggling with immense food insecurity and higher vulnerability to climate change and natural resource degradation. Crop-rotation has been praised for its contribution to sustain agriculture. For example Bullock (1992) observed a 5-20\% increment in yield when farmers rotated Maize and Soybean every two years. Researchers strongly recommend the rotation of cereals with legumes to enjoy increased yield (eg. Stevenson and Kessel, 1996; Torbert et al, 1996; Stanger and Lauer, 2008).

Farmers can also enjoy short-run benefits of crop rotation resulting from market gain and cost reduction. By growing different crops in different periods, farmers can effectively protect themselves from lower prices, resulted from excess supply. Additionally, farmers can save money by minimizing or completely replacing chemical fertilizers, herbicides and pesticides. Growing different crops in different cropping period can also serve farmers as a risk reduction strategy. Farmers can increase their resilience to climate variability by rotating crops instead of mono-cropping (Tilman et al., 2002; Karlenet al., 1994; Liebman and Dyck, 1993).

Traditionally, Ethiopian farmers also practice crop rotation. Unfortunately, policy focus has been exhaustively directed towards the promotion of chemical fertilizers. Some studies have been conducted to analyze the effects of rotation on crop yield and have found a significant and positive relationship (eg. Gorfu, 1990; Tanner et al, 1999). Most researches focus on identifying the determinants of fertilizer and improved seed adoption neglecting the adoption of sustainable practices, such as crop rotation. The knowledge of the determining factors will help design policy and extension service that promotes the use of crop rotation. Unfortunately, there is only one empirical research by Ahmed (2014) that analysed the determinants of crop rotation use in Arsi Negelle, Ethiopia. The present article will be an addition to the literature pertaining to sustainable agriculture.

The study area, east Hararghe, is known for the cultivation of groundnuts, maize and sorghum in rotation. However, not all farmers practice crop rotation, which makes it important to investigate why some farmers are practicing crop rotation while others are not. The objective of the present research is, therefore, to unravel the demographic, economic and institutional factors that are behind the farmer's decision to practice crop rotation.

\section{DATA AND METHODS}

\section{Description of the study area}

This research is conducted based on sample farm households, drawn from three districts of east Hararghe; namely, Babile, Gursum and Fedis. Those areas are potential growers of groundnuts, coffee, khat, maize and sorghum. khat is a stimulating herb widely consumed in the country and is widely exported. The average landholding in the area is 0.5 hectare. The districts have kola (altitude 500-1500/1800m) and woynadeda (altitude 1500-2300m) agro-ecology.

\section{Sampling design and data type}

A quantitative data is collected by using a two-stage sampling technique. In the first stage, three districts are purposively selected, based on similarity in their farming systems. Next, 301 farm households are selected randomly and proportionately to the size of the districts. A structured questionnaire is administered by trained enumerators to gather data on various socio-economic and institutional variables. Due to missing data problem 299 observations are used in the regression analysis.

\section{Methods of data analysis}

The prime motive of this study is to unravel the factors that facilitate or constrain the practice of crop rotation. It is therefore clear that the nature of the dependent variable is binary i.e, a farm household either practices crop rotation or not. In such circumstances, either logit or probit model appears appropriate (see the application of these models in: Adeogun et al., 2008; Fufa and Hassen, 2006; Chianu and Tsujii, 2004; Nkamleu and Adesina, 2000). The logistic regression and the probit model are widely used because they enable us to conduct regression analysis on non-linear independent variables, in this case practicing crop-rotation or not practicing it.

The two models are nearly the same. The basic difference arises from their assumption of the nature of the distribution function of the residuals, where probit assumes normal distribution, while logit assumes a logistic distribution. The logit model is preferred in health research whereas probit is preferred in political and economic research. Therefore, this study uses the probit model to identify the factors that contribute or hinder the decision of farm households whether to practice crop rotation or not. The probit model is specified as follows;

$y^{*}=\beta_{0}+\beta_{1} X+\mu$

and

$\left\{\begin{array}{l}Y=1 ; \text { if } y^{*}>0 \\ Y=0 ; \text { if } y^{*} \leq 0\end{array}\right.$

where, $y^{*}$ is the latent variable, $X$ is vector of random variable and $\mu$ is the error term independent of $x$ and can have either a logistic or normal distribution. The normal distribution is preferred by economists making the probit model more attractive (Wooldridge, 2009).

From equation 1:

$P_{r}\left(Y_{i}=1\right)=P_{r}\left(\beta_{0}+\beta_{1} X_{1 i}+\beta_{2} X_{2 i}+\cdots+\beta_{k} X_{k i}+\right.$
$\mu_{i}>0$

By rearranging equation 2,

$P_{r}\left(Y_{i}=1\right)=P_{r}\left(\mu_{i}>-\left(\beta_{0}+\beta_{1} X_{1 i}+\beta_{2} X_{2 i}+\cdots+\right.\right.$ $\left.\left.\beta_{k} X_{k i}\right)\right)=1-P_{r}\left(\mu_{i}<-\left(\beta_{0}+\beta_{1} X_{1 i}+\beta_{2} X_{2 i}+\cdots+\right.\right.$ $\left.\left.\beta_{k} X_{k i}\right)\right)=1-F\left(-\left(\beta_{0}+\beta_{1} X_{1 i}+\beta_{2} X_{2 i}+\cdots+\right.\right.$ $\left.\beta_{k} X_{k i}\right)$ ) 
where, $F$ is the cumulative density function of $\mu$. By taking the normality of $\mu$ assumption of the probit model;

$$
\begin{aligned}
& P_{r}\left(Y_{i}=1\right)=1-\Phi\left(-\left(\beta_{0}+\beta_{1} X_{1 i}+\beta_{2} X_{2 i}+\cdots+\right.\right. \\
& \left.\left.\beta_{k} X_{k i}\right)\right)=1-\Phi\left(-X_{i} \beta\right)=\Phi\left(X_{i} \beta\right)
\end{aligned}
$$

$\Phi$ is the cumulative normal distribution function. Now, the coefficients $(\beta)$ and standard errors can be computed by using the maximum likelihood estimation technique (Nagler, 1994).

\section{Variables and hypothesis}

Crop rotation: is the dependent variable. It takes 1 if the farmer rotates his/her crops, and 0 if not. The independent variables, that are expected to explain farmer's decision whether to practice crop rotation or not, are presented below with their respective hypothesis.

Age of the household head and age squared: are continuous variables. The expected relationship with crop rotation is negative for younger farmers and positive for older ones with expected signs negative for age and positive for age-square. This is because; younger farmers incline towards the adoption of chemical fertilizers whereas older farmers stick to the "old" practice (eg. Nkegbe et al. 2011).

Gender of the household head: is a dummy variable which takes 1 if male and 0 if female. This variable is expected to have a mixed effect.

Education of household head: is the number of years of schooling the household head attended. A negative relationship is expected with the decision to practice crop rotation. This is because; the more educated farmers are, the more they depend on chemical inputs and tend to consider crop rotation as a traditional practice. In many adoption researches, education is found to positively contribute to the adoption of chemical fertilizers (Olwande, 2009).

Farming experience: is the number of years since the farmer started farming. The expected relationship is positive because, experienced farmers are more likely to understand the benefits of crop rotation. This could also be attributed by the perception of the side effects of inorganic fertilizer application (Olwande, 2009). There is a belief among farmers that continuous inorganic fertilizer application exhausts soil and makes it dependent on it. As a result, they might tend to rehabilitate their land by applying organic fertilizer and crop rotation instead.

Membership in farmer's cooperatives: is a dummy variable, 1 if the farmer is a member of any cooperative, 0 otherwise. This variable is expected to have a negative contribution to farmer's decision to use crop rotation. Cooperative members have access to chemical fertilizers, which could discourage them from choosing to practice crop rotation.

Social responsibility: is another dummy variable which takes 1 if the respondent takes some responsibility in the community; such as, chairperson of self-help groups (equib and Idir), PA administration, etc. It is therefore, highly likely that they depend on chemical fertilizers. This could be attributed to the fact that farmers with social responsibilities are the first ones to be approached by extension agents in their effort to promote and control the use of chemical fertilizers.

Land size: is a continuous variable measured by qoxi, a traditional measure where 8 qoxi is equal to 1 hactare. The variable indicates the size of land owned by sample farmers. The effect could be positive or negative. Larger farm holders might be more commercial oriented hence may prefer to mono crop by using chemical fertilizers. On the other hand, farmers with larger farm could prefer to crop rotate, because they have larger area where they can grow the crop they want on some plots/parts of their land and cultivate legumes on the rest. And next production year, they reverse the plots. However, farmers who have small land might not afford to partition it further and cultivate different crops.

Irrigation: is a dummy variable which takes 1 if the farmer uses irrigation and 0 if not. Irrigation is expected to have a positive contribution to crop rotation. This is because, usually, cereals are grown in the main production season using rainfall, and vegetables and legumes are irrigated.

Distance to farmers training center (FTC): is measured in minutes of walking to the nearest FTC. A negative relationship is expected because the closer farmers are to an FTC, the higher their probability to participate in trainings and demonstrations of "improved" technologies such as fertilizers, which can be translated into non crop rotation.

Distance to market: this is measured in minutes of travel from ones home to the nearby market. A negative relationship is expected because; farmers closer to the market are most likely to focus on mono cropping and commercializing their produce since they can buy what is needed for home consumption. However, farmers who are far away would have to produce a mixture of products as they are unable to buy food items needed for home consumption, enabling them to crop rotate.

Extension frequency: is the number of times farmers were visited by an extension agent in one year. This is expected to have a negative effect on crop rotation as the extension focus in Ethiopia is chemical fertilizer.

Farmer's perception of soil fertility: this variable is important to capture how the perception of farmers towards their soil fertility would affect their decision to practice crop rotation. This variable is classified into three levels; good, medium and low. Farmers with the perception of low soil fertility are expected to practice crop rotation unlike farmers with good and medium perceptions. When farmers get the impression that soil fertility is declining, they are expected to practice sustainable practices such as manure application and crop rotation.

\section{RESULTS AND DISCUSSION}

\section{Descriptive statistics}

The means of the explanatory variables for the whole sample (pooled), for crop rotation users and for non-users are presented in Table 1. There is no significant difference between users and non-users in many of the explanatory variables except for sex of the household head, land size, irrigation use and distance from farmers training center. 
Non users have a shorter distance from farmers training center, which could mean that they are persuaded by the continuous trainings on chemical fertilizer. $20 \%$ of crop rotation non users are female headed households whereas, only $12 \%$ female headed households use crop rotation. Land size is another variable that varies significantly between the two groups where users have 8.64 qoxi while non users have 6.89 qoxi. The use of irrigation is generally low in the study area where only $5.6 \%$ of sample respondents are users. Out of that, $9 \%$ of crop rotation users use irrigation but the percentage for non-users is $2 \%$.

Out of the 299 randomly selected sample respondents, $155(51.8 \%)$ practice crop rotation whereas $144(48.2 \%)$ do not. Crop rotation users in the study area practice a short period rotation of legume-cereal- specifically, groundnuts with sorghum or maize.

\section{Result of the Econometric model}

The regression results of the probit model are presented in Table 2. The model is well fitted with a Prob $>\mathrm{chi}^{2}=$ 0.0001 .

Age and age square affect the decision of farmers to practice crop rotation negatively and positively, respectively. This could be due to the fact that, younger farmers are more accepting of new technologies, such as chemical fertilizers, and substitute them for sustainable alternatives, such as crop rotation. The threshold of age is found to be 36.6 years. The odds of farmers younger than 37 years of age, to use crop rotation decreases by $9 \%$ whereas, a 1 percent increase in age of older farmers (>37years) increases the probability of using crop rotation by $29.7 \%$. Many previous studies on chemical fertilizer adoption have found older farmers adopting less than younger farmers (see for example Olwande, 2009; He et al., 2008; Fufa and Hassen, 2006).

Land size is also found to positively contribute to crop rotation, where a 1 qoxi increase in farm land increases the probability of using crop rotation by $6.6 \%$. Farmers with larger land sizes have the capacity to plant some portion of their land with legume and the rest with cereals in one production season and reverse the order in the coming production season. However, if the farmer has a small land, he/she wouldn't have the capacity to further fraction small land to cultivate it with different crops may not be attractive to farmers (Marenya and Barrett, 2006).

Farmers who use irrigation ipso facto use crop rotations. By using irrigation farmers have multiple productions per year. This contributes positively to the diversification of crops cultivated by the farmers. Farmers mostly produce non cereals if they use irrigation and cultivate sorghum or groundnuts in the rain-fed production period (Arellanes and Lee, 2003). Based on the results of this study, farmers who use irrigation are $10.2 \%$ more likely to practice crop rotation.

Distance from market negatively affects farmer's decision to practice crop rotation. A 1 minute increase in walking time decreases the probability of the use of crop rotation decreases by $2.8 \%$. This could be because, farmers closer to markets may be more commercial oriented, and focus on mono-cropping. They can also purchase items that are needed for household consumption from the market. On the other hand, farmers that are farther from markets may be discouraged by the distance from markets to produce one crop and trade for consumption goods. Instead, they might prefer to produce combination of cereals, legumes and vegetables for subsistence, which in the process leads crop rotation.

The perception of farmers towards the fertility of their soil is found to positive, which is the opposite of the hypothesis. A negative relationship was expected on the assumption that farmers would turn to sustainable options when they regard that fertility is declining. However, the positive significant result indicates that farmers, who perceive that their soil has good and medium fertility, use crop rotation unlike farmers who perceive lower soil fertility.

As hypothesized, distance to farmers training center (FTC) has a positive effect on the decision of farmers to crop rotate. A one minute increase in minutes of walking from an FTC increases the probability using crop rotation by $25.4 \%$. The Farmers nearby FTCs are most likely to be persuaded by the idea of chemical fertilizers in response to the trainings they receive from development agents. However, farmers farther from FTCs are less likely to be persuaded by chemical fertilizers, therefore, they use sustainable ways to keep their land s fertile.

Table 1: Descriptive statistics of explanatory variables

\begin{tabular}{llrrr}
\hline Variables & Obs. & \multicolumn{1}{c}{ Pooled } & Users(N=155) & Non-users(N=144) \\
\hline Age of the household head & 301 & $37.84(11.76)$ & $37.76(.86)$ & $38.11(1.08)$ \\
age2 & 301 & $1570.20(991.53)$ & $1537.73(69.73)$ & $1619.13(93.46)$ \\
Education & 301 & $1.22(2.39)$ & $1.16(.18)$ & $1.27(.21)$ \\
Sex of household head & 301 & $.85(.36)^{* *}$ & $.88(.03)$ & $.80(.03)$ \\
Farming experience & 301 & $20.03(10.43)$ & $19.84(.76)$ & $20.38(.95)$ \\
Cooperative membership & 301 & $.55(.50)$ & $.51(.04)$ & $.60(.04)$ \\
Social Responsibility & 301 & $.39(.49)$ & $.38(.04)$ & $.39(.04)$ \\
Land size & 301 & $7.74(4.40)^{* * *}$ & $8.64(.39)$ & $6.89(.31)$ \\
Irrigation & 247 & $.056(.32)^{* *}$ & $.09(.04)$ & $.02(.01)$ \\
Distance to the market & 299 & $5.29(6.96)$ & $4.45(.41)$ & $6.22(.71)$ \\
Extension frequency & 301 & $66.31(78.93)$ & $64.30(6.35)$ & $67.58(6.55)$ \\
Soil fertility good & 301 & $.70(.46)$ & $.72(.04)$ & $.68(.04)$ \\
Soil fertility medium & 301 & $.27(.45)$ & $.27(.04)$ & $.27(.04)$ \\
Soil fertility low & 301 & $.03(.17)$ & $.01(.00)$ & $.05(.02)$ \\
Distance to FTC & 301 & $1.30(1.42)^{* * *}$ & $1.55(.13)$ & $1.04(.09)$ \\
\hline Note: ***,*** indicate the significance levels at $10 \%, 5 \%$ and $1 \%$ respectively. Source: own estimation
\end{tabular}


Table 2: Probit model result

\begin{tabular}{lrrr}
\hline Variables & Coefficients & Marginal effects & Std Err. \\
\hline Age of household head & $-.090^{*}$ & -.036 & .046 \\
lnAge square & $2.970 *$ & 1.183 & 1.701 \\
Education & .048 & .019 & .042 \\
Sex of household head & .056 & .022 & .255 \\
Farming experience & .010 & .004 & .016 \\
Cooperative membership & -.035 & -.014 & .231 \\
Social responsibility & .053 & .021 & .221 \\
land size & $.066 * * *$ & .026 & .023 \\
Irrigation & $1.021 * *$ & .407 & .402 \\
Distance to market & $-.028 * *$ & -.011 & .014 \\
lnextension frequency & .038 & .015 & .064 \\
Soil fertility good & $2.530 *$ & .033 & 1.373 \\
Soil fertility medium & $2.448 *$ & -.500 & 1.382 \\
Soil fertility low & omitted & & \\
Distance to FTC & $.254 * *$ & .101 & .078 \\
cons & $-10.828 * * *$ & & 4.612 \\
\hline Note: $* * *, * * *$ indicate the significance levels at $10 \%, 5 \%$ and $1 \%$ respectively.
\end{tabular}

Note: $* * *, * * *$ indicate the significance levels at $10 \%, 5 \%$ and $1 \%$ respectively.

Source: own estimation

\section{CONCLUSIONS AND RECOMMENDATION}

Crop rotation, as any of the sustainable agricultural practices, has many advantages. Improving soil fertility, controlling for weeds and pests and enhancing yield are among the major advantages of crop rotation. However, the practice is not obtaining enough attention, especially in developing countries like Ethiopia where the focus of development agenda is towards the use of "new" technologies such as chemical fertilizers and herbicides. However, the use of these new technologies has its own negative side effects, especially to the sustainability of agriculture. Based on the findings of this research, older farmers practice crop rotation than their younger counterparts. Therefore, by creating experience sharing platforms for farmers, crop rotation can be promoted. The other significant variable is distance from FTC, indicating the need for designing trainings pertaining to crop rotation. Distance to the Market is also a positive factor affecting crop rotation. It is therefore; relevant to create awareness by educating market oriented farmers to diversify their production and at the same time maintain their soil. Another positive factor is land size. Unfortunately, land is further being fragmented due to the growing population. Therefore, designing policies that create non-agricultural career to the young rural dwellers could minimize the problem.

\section{REFERENCES}

ADEOGUN, O. A., AJANA, A. M., AYINLA, O. A., YARHERE, M. T. and ADEOGUN, M. O. (2008). Application of logit model in adoption decision: A study of hybrid clarias in Lagos State, Nigeria. AmericanEurasian Journal of Agriculture and Environmental Sciences 4 (4): 468-472.

AHMED, M. H. (2014). Farmer's Decision to Practice Crop Rotation in Arsi Negelle, Ethiopia: What are the Determinants? International Journal of Sustainable Agricultural Research, 1(1), 19-27.
ARELLANES, P. and LEE, D.R. (2003). The determinants of adoption of sustainable agriculture technologies: evidence from the hillsides of Honduras. In Proceedings of the 25th International Conference of Agricultural Economists (IAAE), vol. 16, p. 22. https://core.ac.uk/download/pdf/7010172.pdf

BALDWIN, K. R. (2006). Crop rotations on organic farms. North Carolina Cooperative Extension Service. College of Agriculture and Life Sciences. NC State University.

https://georgiaorganics.org/wpcontent/themes/GeorgiaOr ganics/Downloads/pdf/CropRotations.pdf

BULLOCK, D. G (1992). Crop rotation. Critical reviews in plant sciences 11(4): 309-326.

CARDINA, J., HERMS, C. P. and DOOHAN D.J. (2002). Crop rotation and tillage system effects on weed seedbanks. Weed Science 50(4): 448-460. doi: http://dx.doi.org/10.1614/00431745(2002)050[0448:CRATSE]2.0.CO;2

CHIANU, J. N. and TSUJII, H. (2004). Determinants of farmers' decision to adopt or not adopt inorganic fertilizer in the savannas of northern Nigeria. Nutrient cycling in agroecosystems 70 (3): 293-301. Doi:10.1007/s10705005-0715-7

FUFA, B. and HASSAN, R. M. (2006). Determinants of fertilizer use on maize in Eastern Ethiopia: A weighted endogenous sampling analysis of the extent and intensity of adoption. Agrekon $45 \quad$ (1): 38-49. Doi: http://dx.doi.org/10.1080/03031853.2006.9523732

GORFU, A. and TANNER, D.G. (1990). The effect of crop rotation in two wheat production zones of Southeastern Ethiopia. In 3. International Conference on Wheat for the Nontraditional Warm Areas. Foz do Iguacu (Brazil). 29 Jul-3 Aug 1990.

HE, X., CAO, H. and LI, F. (2008). Factors influencing the adoption of pasture crop rotation in the semiarid area of China's Loess Plateau. Journal of sustainable agriculture 32(1):161-180. Doi: http://dx.doi.org/10.1080/10440040802121551 
IFDC (2012). Ethiopia Fertilizer Assessment. Muscle Shoals, Alabama 35662, USA https://ifdcorg.files.wordpress.com/2015/04/ethiopiafertilizer-assessment.pdf

KARLEN, D. L., G. E. VARVEL, BULLOCK D. and CRUSE R. M. (1994). "Crop rotations for the 21st century." Advances in agronomy 53(1):45. Doi: 10.1016/S0065-2113(08)60611-2

LIEBMAN, M. and DYCK, E. (1993). Crop rotation and intercropping strategies for weed management. Ecological applications 3(1):92-122. DOI: $\underline{10.2307 / 1941795}$

LIU, X. B., ZHANG X. Y., WANG Y. X., SUI Y. Y., ZHANG S. L., HERBERT S. J. and DING G. (2010). Soil degradation: a problem threatening the sustainable development of agriculture in Northeast China. Plant soil environ 56(2): 87-97.

MARENYA, P.P. and BARRETT C. B. (2007). Household-level determinants of adoption of improved natural resources management practices among smallholder farmers in western Kenya. Food Policy 32(4):515-536.

Doi:

http://dx.doi.org/10.1016/j.foodpol.2006.10.002

MEKONNEN, H., KEBEDE, K., HASEN, M., \& TEGEGNE, B. (2016). Farmer's Perception of Soil and Water Conservation Practices in Eastern Hararghe, Ethiopia. Problems of World Agriculture/Problemy Rolnictwa Ašwiatowego, 16(31).

NKAMLEU, B. G. and ADESINA, A. A. (2000). Determinants of chemical input use in peri-urban lowland systems: bivariate probit analysis in Cameroon. Agricultural systems 63 (2): 111-121. Doi: http://dx.doi.org/10.1016/S0308-521X(99)00074-8
NKEGBE, P.K., SHANKAR B. and CEDDIA G. M. (2012). Smallholder adoption of soil and water conservation practices in Northern Ghana. Journal of Agricultural Science and Technology. 2(5B): 595.

NLWRA (2001). Australian Agriculture Assessment 2001, Volume 1 (National Land and Water Resources Audit).

OLWANDE, J., SIKEI, G. and MATHENGE M. (2009). Agricultural technology adoption: A panel analysis of smallholder farmers' fertilizer use in Kenya. Center of Evaluation for Global Action.

STANGER, T. F. and LAUER, J. G. (2008). Corn grain yield response to crop rotation and nitrogen over 35 years. Agronomy journal 100(3): 643-650. doi: 10.2134 /agronj2007.0280

STEVENSON, F. C., and VAN KESSEL C. (1996). The nitrogen and non-nitrogen rotation benefits of pea to succeeding crops. Canadian Journal of Plant Science 76(4): 735-745. Doi: $\underline{10.4141 / \text { cjps96-126 }}$

TANNER, D.G., VERKUIJL, H., TAA, A. and ENSERMU, R. (1999). An agronomic and economic analysis of a long-term wheat-based crop rotation trial in Ethiopia.

TILMAN, D., CASSMAN, K.G, MATSON, P.A., NAYLOR, R. and POLASKY, S. (2002). Agricultural sustainability and intensive production practices. Nature $418 \quad$ (6898): 671-677. Doi:10.1038/nature01014

TORBERT, H. A., REEVES, D.W. and MULVANEY, R. L. (1996). Winter legume cover crop benefits to corn: rotation vs. fixed-nitrogen effects. Agronomy journal 88(4): $527-535$ Doi:10.2134/agronj1996.00021962008800040005x 